Kennesaw State University

DigitalCommons@Kennesaw State University

Faculty Publications

$4-2001$

\title{
An Experimental Study of Circuit Breakers: The Effects of Mandated Market Closures and Temporary Halts on Market Behavior
}

Lucy Ackert

Kennesaw State University, lackert@kennesaw.edu

Bryan K. Church

Georgia Institute of Technology - Main Campus

Narayanan Jayaraman

Georgia Institute of Technology - Main Campus

Follow this and additional works at: https://digitalcommons.kennesaw.edu/facpubs

Part of the Other Business Commons, Portfolio and Security Analysis Commons, and the Strategic Management Policy Commons

\section{Recommended Citation}

Ackert, Lucy F., Bryan Church, and Narayanan Jayaraman. "An Experimental Study of Circuit Breakers: The Effects of Mandated Market Closures and Temporary Halts on Market Behavior." Journal of Financial Markets 4.2 (2001): 185-208.

This Article is brought to you for free and open access by DigitalCommons@Kennesaw State University. It has been accepted for inclusion in Faculty Publications by an authorized administrator of DigitalCommons@Kennesaw State University. For more information, please contact

digitalcommons@kennesaw.edu. 


\title{
An Experimental Study of Circuit Breakers: The Effects of Mandated Market Closures and Temporary Halts on Market Behavior
}

\author{
Lucy F. Ackert, Bryan K. Church, and Narayanan J ayaraman \\ F ederal Reserve Bank of Atlanta \\ Working Paper 99-1 \\ March 1999
}

\begin{abstract}
This paper analyzes the effect of circuit breakers on price behavior, trading volume, and profit-making ability in a market setting. We conduct nine experimental asset markets to compare behavior across three regulatory regimes: market closure, temporary halt, and no interruption. The presence of a circuit breaker rule does not affect the magnitude of the absolute deviation in price from fundamental value or trading profit. The primary driver of behavior is information asymmetry in the market. By comparison, trading activity is significantly affected by the presence of a circuit breaker. Mandated market closures cause market participants to advance trades.
\end{abstract}

J EL classification: D40, G10, G14

Key words: circuit breakers, trading halts, market structure

The authors thank the F ederal Reserve Bank of Atlanta for financial support, Kendra Hiscox for valuable research assistance, and J in-Wan Cho, J erry Dwyer, Kalpana Narayanan, J o Sinkey, and seminar participants at Georgia Tech and the Atlanta Finance Workshop for helpful comments. The views expressed here are the authors' and not necessarily those of the Federal Reserve Bank of Atlanta or the Federal Reserve System. Any remaining errors are the authors' responsibility.

Please address questions regarding content to Lucy F. Ackert, Research Department, Federal Reserve Bank of Atlanta, 104 Marietta Street, NW, Atlanta, Georgia 30303-2713, 404/521-8783, lucy.ackert@atl.frb.org, or Bryan K. Church or Narayanan J ayaraman, DuPree College of Management, Georgia I nstitute of Technol ogy, Atlanta, Georgia 30332-0520, 404/894-3907 (Church), bryan.church@mgt.gatech.edu, 404/894-4389 (J ayaraman), narayanan. jayaraman@mgt.gatech.edu.

To receive notification about new papers or to order copies of printed papers, contact the Public Affairs Department, Federal Reserve Bank of Atlanta, 104 Marietta Street, NW, Atlanta, Georgia 30303-2713, 404/521-8020. The full text of this paper may be downloaded (in PDF format) from the Atlanta Fed's World-Wide Web site at www. frbatlanta.org/publica/work_papers/. 


\section{An Experimental Study of Circuit Breakers: The $E$ ffects of $M$ andated $M$ arket $C$ losures and Temporary Halts on Market Behavior}

Recent dramatic swings in the U.S. stock market have resurrected the circuit breaker debate though researchers and regulators have reached no consensus on whether circuit breakers provide a moderating influence. Though circuit breakers can take many forms, in this paper we focus on market-wide mandated trading halts triggered by extreme market movements. ${ }^{1}$ Circuit breakers were advocated by the members of the Brady Commission who argued that these mechanisms "cushion the impact of market movements, which would otherwise damage market infrastructures" (Presidential Task Force on M arket M echanisms, 1988, page 66). A merican exchanges instituted circuit breakers in the year following the 1987 market crash in an effort to protect investors and markets in the event of a future extreme market adjustment. Opponents contend that mandated trading halts impede the natural movement of stock prices and introduce unnecessary and artificial barriers.

Though the empirical evidence is scant, theoretical studies have provided insight into the role of circuit breakers in the functioning of financial markets. ${ }^{2}$ Informational problems may be exacerbated when volume shocks are large, in which case mandated halts can play a useful role in reducing transactions risk (Greenwald and Stein (1991)). A lternatively, circuit breakers may have the perverse effect of increasing price variability by forcing agents to advance their trades (Subrahmanyam (1994)). 
Table I details the history of circuit breakers in U.S. security markets. Though trading halt rules have now been in effect for a decade, the breakers have been triggered infrequently. The trading halt rules originally called for trading interruptions of one and two hours when the Dow Jones Industrial A verage (DJIA) fell 250 and 400 points. Because of increases in the level of the market, the point breakers were widened in 1997 and then tied to percentage changes in the DJIA in 1998. ${ }^{3}$

A rchival studies of the effects of circuit breakers encounter numerous empirical demands because it is almost impossible to determine the net effect of breakers on the market. Stock prices and associated volatility may change for a variety of reasons, including the distribution of informed and uninformed traders, macroeconomic factors, and investor sentiment. These changes may or may not be related to shifts in underlying fundamentals. M oreover, archival methods do not permit the researcher to ascertain what would have happened in the absence of circuit breakers. This study uses an experimental approach to investigate the effect of circuit breakers on price behavior, trading volume, and trading profit in a market setting. This approach allows us to control extraneous factors, which although important, create potential confounds when using archival data. Using an experimental method we can specify the level of uncertainty, the distribution of information across traders, and the fundamental determinants of asset value. Importantly, the use of an experimental method allows us to examine behavior under alternative market structures (e.g., in the presence and absence of circuit breakers). Such an examination cannot be conducted in naturally occurring markets. ${ }^{4}$ For our purposes, empirical regularities observed in the laboratory provide insight into the effect of circuit breakers on market performance. 
We conduct nine experimental asset markets to compare behavior across three regulatory regimes: market closure, temporary halt, and no interruption. In the sessions with market closures, no transactions are permitted for the remainder of a trading period if the circuit breaker is triggered. With temporary halts, market activity is interrupted when a price movement triggers the breaker. Finally, in the sessions with no interruptions, market participants are free to transact at any price during the trading period. We conduct three market sessions with each institutional structure. In each market we vary the level of uncertainty and the information asymmetry among traders.

The main conclusions are that the deviations from the expected price are not different in the presence of temporary halts and permanent market closures due to circuit breakers. The primary driver of deviations from fundamental value is the level of information asymmetry in the market. In fact, in periods with greater information asymmetry the deviation is twice as large as that in other periods. Our analysis of trading volume indicates that circuit breakers affect trading activity in a significant way. When we control for the time the market is open for trading, activity is greater in the market closure regime than in the temporary and no halt regimes. The possibility of market closure accelerates trading activity. Finally, circuit breakers do not affect trading profits in a significant way indicating that traders are unable to exploit informational advantages.

The paper is organized as follows. Section I provides a framework. Section II describes our experimental design and procedures. Section III presents empirical tests 
and evidence on market dynamics with and without circuit breakers. Section IV provides discussion of the results and concludes the paper.

\section{Experimental Framework}

Insight into the expected economic impact of a circuit breaker rule is provided by theoretical studies. Greenwald and Stein (1991) provide support for the Brady Commission's argument that circuit breakers provide a calming influence in times of market distress. In their model, buyers withhold orders in response to large volume shocks because transactional risks are high (i.e., buyers are unsure of the final execution price they will receive). Circuit breakers provide time for traders to learn about order flow imbalances and facilitate adjustment of price to equilibrium, because transactional risks are reduced. Circuit breakers confer additional benefits if they protect uninformed investors or allow an exchange to maintain a positive reputation (Kyle (1985)).

Subrahmanyam (1994) offers an alternative stance on the usefulness of circuit breakers. If mandated trading halts cause market participants to suboptimally advance trades, a circuit breaker rule will intensify price movements and increase volatility. ${ }^{5}$ Thus, the effect of the circuit breaker is opposite that intended by regulators. Increases in ex ante trading volume result. A nother drawback of mandated trading halts arises because investors incur costs when markets are closed. Investors may be forced to hold open positions that they would prefer to close (Gerety and M ulherin (1992)).

Empirical evidence regarding the role of circuit breakers in moderating volatility and enhancing efficiency is inconclusive. Though some research focuses on 
the effects of trading restrictions in stock markets (Kuhn, Kuserk, and Locke (1990), Lauterbach and Ben-Zion (1993), Santoni and Liu (1993), Overdahl and M CM illan (1998)), other evidence arises from studies of markets with controls related to circuit breakers. F or example, researchers have examined the price limit rules commonly imposed in futures markets and firm-specific trading halts called at the discretion of exchanges in response to market conditions or news releases. While some researchers have concluded that trading restrictions reduce volatility (M a, Rao, and Sears (1989a, 1989b)), others find that volatility increases (Kuhn, Kuserk, and Locke (1990), Lee, Ready, Seguin (1994)). Still others find that that the trading restrictions have little effect on the market in the long run (L auterbach and Ben-Zion (1993), Santoni and Liu (1993), Overdahl and M CM illan (1998)).

Direct examination of the effect of a market-wide circuit breaker rule on asset price behavior is problematic because breakers have historically been triggered infrequently. Furthermore, providing a valid basis for comparison is difficult because, in naturally occurring markets, we cannot ascertain what would have happened in the absence of the rule. Experimental examinations of the effect of circuit breakers are particularly useful because archival studies are wrought with challenges.

Experimental markets studies have found that even non-binding price controls affect market dynamics and reduce market efficiency (Isaac and Plott (1981), Smith and Williams (1981)). Other research has found that price change rules do not mitigate observed price run-ups and subsequent crashes in experimental asset markets (Smith, Suchenek, Williams (1988), King, Smith, Williams, and Van Boening (1993)). Finally, in their examination of price limits and trading suspensions, Coursey and Dyl 
(1990) found that prices adjust more efficiently when trading is unconstrained and that efficiency losses are higher with trading suspensions as compared to markets with price limits. Our study differs from Coursey and Dyl's in that private information plays an important role. In their study trading is motivated primarily by a desire to rebalance holdings rather than in response to private information.

In our experimental setting, uncertainty exists about the asset's common value and the level of uncertainty varies across traders due to the presence of private information. In naturally occurring asset markets uncertainty about the fundamental value of assets, particularly equities, is present. Prices continually adjust to new information about fundamental value as the information arrives at the market. Because observed volatility in equity markets is likely related to uncertainty about common fundamental asset value, additional investigation of the effects of circuit breaker rules is warranted (Harris (1998)). Furthermore, a subset of agents often has higher quality information, though uninformed traders may behave as if they are informed when private information is reflected in market prices (Grossman and Stiglitz $(1976,1980)$ ). With our experimental approach we provide insight into the empirical and theoretical debate surrounding the effect of a circuit breaker rule in asset markets.

A fter describing our experimental design and procedures, we examine price behavior, trading volume, and individuals' trading profits. We investigate the absolute deviation in trading price from fundamental value, where such value is measured by the risk-neutral expected price. Fundamental value is computed simply as the expectation of the asset's payoff conditioned on available information. Our design allows us to 
directly examine whether market closures and temporary halts provide a cooling off period, or exacerbate deviations in prices from fundamentals.

We also assess whether prices reflect new information as it arrives at the market. Experimental research has shown that private information is reflected in asset prices (Copeland and Friedman (1992), Sunder (1992), and A ckert, Church, and Shehata (1997)). In our experiment, we vary information asymmetry across trading periods. In some periods, traders have common information and in other periods a subset of traders is privately informed. We investigate whether mandated closures and temporary halts affect information dissemination in periods with private information.

N ext we examine whether trading volume is affected by the presence of a circuit breaker rule. Subrahmanyam (1994) suggests that volume is higher with mandated trading interruptions. We investigate whether market participants advance trades in anticipation of a trigger of the circuit breaker rule.

Finally, we examine whether informed traders can persistently take advantage of their superior information by generating greater trading profits. If private information is immediately reflected in market prices, informed traders should not consistently outperform uninformed traders. However, if private information is not immediately disseminated, informed traders may generate excess profit. A circuit breaker rule may not prevent the informed from prospering at the expense of the uninformed. Previous experimental results are mixed (Sunder (1992), A ckert, Church, and Shehata (1997), Ackert and Church (1998)). 


\section{Experimental M ethod}

A. Design

Nine experimental asset markets are conducted. Each market includes 6 years and each year consists of three periods. All markets have 8 traders and all traders are inexperienced in that none participated in an earlier session. Table II provides an overview of the experimental parameters. In markets 1-3 trading is shut down on a permanent basis if a circuit breaker is triggered. The actual procedure used for closure is described subsequently. In markets 4-6 trading is halted on a temporary basis if an extreme price movement activates a circuit breaker. Finally, in markets 7-9 participants are free to transact without any threat of a trading interruption.

Each year market participants trade certificates with three-period lives, referred to as periods $A, B$, and $C$. At the end of each period participants receive a common dividend for each certificate held. ${ }^{6}$ Certificates are not carried across years. Thus, the payoff to a certificate held throughout all periods in a year is the dividends paid in periods $A, B$, and $C$.

The level of uncertainty and asymmetry of information are varied within markets and across traders. Each year, the period A dividend is drawn from a distribution known to all participants. The dividends for periods $B$ and $C$ are also drawn from a given distribution, but the specific distribution is unknown at the beginning of the year. At the beginning of period $B$, two traders receive information that narrows the distribution of possible dividend values. ${ }^{7}$ At the start of period $C$ this information is made public to all traders. Hence, price uncertainty diminishes as trading progresses from period $A$ to $C$. Overall, our design provides a basis from 
which we can compare the effect of permanent and temporary trading interruptions on market price dynamics, trading volume, and profit-making ability.

\section{B. Procedures}

At the beginning of each market session participants receive a set of instructions which an experimenter reads aloud. ${ }^{8}$ Substantially all participants were master's students at Georgia Tech who had successfully completed a required finance course or were currently enrolled in the course. The average compensation across the 72 traders in our markets was $\$ 30.35$, which includes trading earnings, a $\$ 3.00$ bonus if on time for the session, and $\$ 2.00$ for completing a post-experiment questionnaire. The markets take approximately two hours to complete.

Each trader is endowed with certificates and cash at the beginning of the trading session. There are four endow ment classes with two traders receiving the same endowment. The specific endowments are summarized in Table II. These endowments are assigned randomly prior to the start of each year from the set of four possible endowments given in Table II.

During each market year participants trade certificates with three period lives. All markets are organized as double oral auctions. Traders are free to make verbal offers to buy or sell one certificate at a designated price at any time, and all offers are publicly announced and recorded. Outstanding offers stand until accepted or replaced by a better bid or ask price. Short sales are not permitted. If a circuit breaker is not triggered, all market periods last 3 minutes. Participants are not informed of the number of years to be conducted. 
Uncertainty regarding the actual dividend exists until the market closes for the period. The dividend paid in period $A$ is always selected randomly from distribution III given in Panel B of Table II. Participants are informed of the distribution beforehand and told that each dividend is equally likely so that the mean of the distribution is $\$ 5.00$. The dividends for periods $B$ and $C$ are drawn from one of the five distributions given in Table II with the constraint that the dividends are drawn using the same distribution for periods $B$ and $C$ within the same trading year. N ote that this does not imply that the period $B$ and $C$ dividends are equal, but only that they have an equal ex ante expectation. The experimenters randomly determine the actual distribution for periods $B$ and $C$ prior to the experiment and the same sequence of distributions is used across all markets. ${ }^{9}$ At the beginning of period $B$, two traders are provided with information concerning the distribution from which period $B$ and $C$ dividends are drawn. ${ }^{10}$ The other traders know only what they can infer from the trading behavior of others until the end of period $B$, at which time the experimenters announce the distribution to all the participants. The procedures repeat in years 2-6.

D uring each trading period, participants are free to trade certificates in the no interruption condition. However, in the market closure and temporary halt conditions, trading can be halted or interrupted when there are large upward or downward price movements in the market for all certificates. Our circuit breaker rules are designed to reflect the fact that actual rules tie interruptions in trading to movements in the overall market, as measured by the DJIA. Participants are told that market movements are positively, but not perfectly, correlated with the prices of the certificates they trade. 
A fter each completed transaction, the trading interruption rule is assessed. In period $A$, the circuit breaker rule is implemented as follows. The probability of a trading halt increases as the price moves away from $\$ 15.00$, the expected value of a certificate. The probability of a halt is 50 percent if the price moves more than 5 percent but less than 10 percent from $\$ 15.00$. The probability of a halt increases to 90 percent if the price moves 10 percent or more from $\$ 15.00$. The circuit breaker rules in period $\mathrm{B}(\mathrm{C})$ are constructed similarly with the permissible trading price ranges centered about the last transactions price in period A (B) less $\$ 5.00$, the average oneperiod dividend value. ${ }^{11}$ A $n$ experimenter determines whether trading actually halts by drawing a card from one of two decks. The first set has 5 (5) cards labeled "stop" ("go") and the second has 9 (1) labeled "stop" ("go").

In the market closure condition, the market does not reopen until the following market period if a breaker is triggered. In the temporary halt condition, trading is suspended for 30 seconds. A fter a suspension, trading resumes as before with the circuit breaker rule for transaction price ranges centered around the last transaction price prior to the trading interruption. However, trading is never halted in the last 60 seconds of a period.

A fter the experimenter announces the year's dividend, traders calculate their cash balance by multiplying the number of certificates held by the dividend and adding their earnings from certificate holdings to their cash on hand. Certificates and cash are carried forward across periods within a market year (but not across years). At the end of period C, participants keep cash in excess of a fixed cost of $\$ 100$. Each trader's endowment is reinitialized at the start of a new market year. 
At the end of the experiment participants are paid in cash. Trading profit is converted to take-home earnings by multiplying profit by 10 percent. During this time, participants complete a post-experiment questionnaire. Participants receive additional compensation of $\$ 2.00$ in order to provide them with an incentive to carefully complete the questionnaire. The purpose of the questionnaire is to collect general information about the traders and how they viewed the experiment. ${ }^{12}$

\section{Results}

We report the results of the nine experimental markets subsequently. Subsection A provides descriptive information on the time that each market is open as well as the frequencies of halts and transactions across years. Subsections B, C, and D provide analyses of price behavior, trading volume, and trading profit, respectively.

\section{A. Descriptive information}

Table III provides descriptive data on trading time for the mandated closure and temporary halt regimes. Trading may last a maximum of 180 seconds per period and, in the no interruption sessions, markets are always open the maximum amount of time. In the two halt regimes, circuit breakers are often triggered. The average trading time is 88 (160) seconds with mandated market closures (temporary halts). Trading time is greater in markets with temporary halts because trading al ways resumes after a circuit breaker is triggered. Further, the data indicate that markets are open longer in period A than periods B and C, with little noticeable difference across years. 
Table IV presents the number of halts and draws by period and year for the two halt regimes. The observed frequencies are nearly identical in the market closure and temporary halt regimes. ${ }^{13} \mathrm{~N}$ ot surprisingly, fewer halts and draws are observed in period A, but no pattern is evident across years. Table IV also presents the total number of transactions by period and year for all three market structures. The transactions data are consistent with the time the markets are open. The number of transactions is largest with no interruptions, slightly less with temporary halts, and smallest with market closures. In addition, more transactions are observed in period A than periods $B$ and $C$. As before, no differences are evident across years.

\section{B. Price Deviations}

We examine price deviations from fundamental value, where such value is determined by the risk-neutral expected price. In periods A and C, information is common to all market participants. In period $\mathrm{B}$, the expected price is determined assuming that private information is disseminated. The expected prices by year and period are summarized in Table V, along with the randomly selected distribution from which the dividend per period is drawn.

To provide insight into whether prices converge to expected value, we first examine the time series of transaction prices across periods and years for each market. Figures 1 through 6 detail transaction prices across periods A-C within a year for selected markets. Figures 1 through 3 (4 through 6) depict selected transaction price series for year 5 (6). For each year, we select a market from each regulatory regime: figures 1 and 4, 2 and 5, and 3 and 6 are from the market closure, temporary halt, and 
no interruption regimes, respectively. The figures include the circuit breaker in place, as detailed previously, and the expected price per period. The figures show that asset prices roughly converge to the expected price and are not consistently above or below predictions. ${ }^{14} \mathrm{~N}$ otably, in sessions with market closures (Figures 1 and 4 ) and temporary halts (Figures 2 and 5) prices appear to move toward the expected price despite the circuit breaker rule in place. In addition, the private information, held by a subset of traders in period B (the informed traders), appears to be reflected in market prices. Transaction prices move toward the expected price that is calculated assuming dissemination of private information.

To further investigate price behavior in period B we count the number of times that the last price in period $B$ reflects the dividend distribution known only to informed traders. We use the last transaction price because earlier prices are informative. The last price is not inconsistent with private information if it falls between two times the low and high values of the dividend distribution. We multiply the minimum and maximum dividends by two because the distribution determines the dividends paid in periods $B$ and $C$. Consider the following example for illustrative purposes. If private information indicates that distribution IV is used to determine dividends (refer to Table II), the asset price in period B should fall between $\$ 9$ (two multiplied by $\$ 4.50$ ) and $\$ 15$ (two multiplied by $\$ 7.50)$.

U sing data across years 1-6, we find that the last price is not inconsistent with private information in 12 of 18 cases, 14 of 18 cases, and 17 of 18 cases in the mandated closure, temporary halt, and no interruption regimes, respectively. We perform a chi-square test to determine whether differences arise across market 
structures. The $P^{2}$-statistic is not statistically significant $\left(P^{2}=4.338, p=0.114\right)$ and suggests that market structure does not affect information dissemination.

$\mathrm{N}$ ext we formally test the effect of a circuit breaker rule on deviations in price from fundamental value across all periods. We perform an analysis-of-variance (A NOVA), where the dependent variable is the absolute value of the deviation in price from the predicted price, normalized by the predicted price. In periods A and C, we use the median transaction prices. ${ }^{15}$ In period B we use the last transaction price. The independent variables include market structure (market closure, temporary halt, and no interruption), period ( $A, B$, and $C)$, and an interaction term. Period proxies for the information asymmetry among traders within a market year, with greater asymmetry in period $B$ than in periods $A$ and $C$. The level of price uncertainty also varies across periods, with uncertainty decreasing from period $\mathrm{A}$ to period $\mathrm{C}$.

The AN OV A results using data from years 1-6, presented in Panel A of Table VI, indicate that period is significant at $p<0.001$ and the interaction term is marginally significant at $p=0.074$. The significant main effect arises because the mean price deviation in period $B(0.2097)$ is greater than that in periods $A(0.0639)$ and C (0.1086). Tukey HSD multiple comparison tests (Hays (1981)) indicate that the mean deviation in period $B$ is significantly different from the mean deviations for the other two periods at $p<0.01$. The greater period $B$ mean likely results because private information creates differences in expectations, whereas in periods $A$ and $C$ the absence of private information results in common expectations.

To assess the statistical significance of the interaction term, we perform additional analyses. We find that period significantly affects price deviations in the 
market closure and temporary halt groups. Tukey HSD tests indicate that period B is significantly different from the other two periods at $p<0.01$, with the greater deviation in period B. Notably, information asymmetry is present in period B and not in periods $A$ and $C$. Inspection of the data suggests that period is not statistically significant for the no halt group because of large price fluctuations at early stages of trading (i.e., the first 3 years). This initial large variation is not surprising. With the circuit breaker rule traders, in effect, receive direction in setting prices, whereas in the no halt group they are given no guidelines.

We repeat the ANOVA excluding data from years 1-3. A nalysis of price behavior excluding data from the initial trading years may be more informative because traders are given the opportunity to gain an understanding of the mechanics of the market and behavior settles down. Previous studies of experimental asset markets find that an initial learning phase often occurs before behavior stabilizes (e. g., Williams (1980), Forsythe, Palfrey, and Plott $(1982,1984))$. Panel B of Table VI reports the A N OV A results using data from years $4-6 .{ }^{16}$ Only the period variable is statistically significant $(p=0.003)$. The data indicate that, on average, price deviations from fundamental value are larger in period $B(0.1185)$, than in periods $A(0.0415)$ and $C$ (0.0546). Tukey HSD tests indicate that the mean deviation in period B is significantly different from the mean deviations in the other two periods at $p<0.01$. We do not find a significant difference across market structures. Thus, the primary driver of deviations from the expected price is the level of information asymmetry in the market. 


\section{Trading Volume}

We examine trading volume across the three regulatory regimes. As noted previously and shown in Table IV, the total number of transactions decreases across the no interruption, temporary halt, and market closure groups. Correspondingly, the average numbers of transactions per period are 5.54, 4.93, and 2.78, respectively. Tukey HSD tests indicate that the market closure group is significantly different from the other two groups at $p<0.001$. This result indicates that fewer trades occur when the potential for market closure is present. However, to formally assess the effect of market structure on trading activity, we must control for the time that the market is open.

We perform an ANOVA to formally test the effect of the circuit breaker rule on trading volume where the dependent variable is the number of transactions per period normalized by the number of seconds that the market is open for trading. ${ }^{17}$ As before, the independent variables are market structure (market closure, temporary halt, and no interruption), period (A, B, and C), and an interaction term.

The results are presented in Table VII. U sing data from years 1-6, the market and interaction variables are significant at $p<0.01$. The significant main effect arises because the trading activity in the market closure regime $(0.0427)$ is greater than that in the temporary (0.0312) and no halt regimes (0.0308). Tukey HSD tests indicate that the market closure regime is significantly different from the other two regimes at $p<$ 0.01

To assess the statistical significance of the interaction term, we perform additional analyses. We find that for periods $A$ and $C$, market is not statistically 
significant at conventional levels. For period B, market is statistically significant at $p<0.001(F=9.553, d f=2,53)$. Tukey HSD tests indicate that the market closure group is significantly different from the other two groups at $p<0.01$, with more trades occurring per second in the closure regime. These findings are consistent with Subrahmanyam (1994) who shows that circuit breakers may force market participants to advance their trades.

Panel B of Table VII reports the A N OV A results using data for years 4-6. $M$ arket is statistically significant and the data suggest that, on average, volume per second is largest in the market closure treatment. A gain Tukey HSD tests indicate that the market closure regime is significantly different from the other two regimes at $p<$ 0.01 , with more trades occurring per second in the closure regime. The decreasing uncertainty and varying information asymmetry across periods do not have significant effects on trading activity.

To provide further insight into the effect of a circuit breaker rule on volume, we examine whether trading activity varies across informed and uninformed traders. We perform a multivariate A NOVA to test whether market structure affects trading activity in period $\mathrm{B}$. The dependent variables are the number of transactions per year for informed and uninformed traders normalized by the length of trading time and the independent variable is market structure. The multivariate results indicate that market structure is significant at $p=0.006$ using data for years $1-6(F=3.818, d f=4,102)$ and at $p=0.092$ for years $4-6(F=2.128, d f=4,48)$. The univariate results, reported in Table VIII, indicate that market structure has an important effect on trading activity, regardless of whether a trader is informed. As shown in Panels A and B, the 
result holds using data for years 1-6 and 4-6. A dditional investigation indicates that the numbers of trades for the informed and uninformed are greater when a circuit breaker may result in market closure than when trading may resume after a halt or in the absence of halts.

\section{Trading Profits}

We perform an ANOVA to formally test the effect of market structure on traders' abilities to generate profit. The dependent variable is the profit generated per trader each year. ${ }^{18}$ The independent variables include market structure (market closure, temporary halt, and no interruption), informedness (informed and uninformed), and an interaction term. The results reported in Table IX indicate that when the analysis includes data from years 1-6 or 4-6 none of the independent variables significantly impact trading profit at $p<0.05$. Y et when the analysis focuses on the initial trading years (1-3), informedness has a significant effect on trading profit at $p<0.001(\mathrm{~F}=$ 15.005, $d f=1,216)$. The data indicate that the mean profit per year of informed $(\$ 41.39)$ is greater than that of uniformed traders $(\$ 29.17) .{ }^{19}$ The superior profitmaking ability of the informed, however, does not persist throughout the experiment. These results are consistent with A ckert and Church (1998).

If market prices reflect private information, we might expect to find no differences in profit across informedness groups. Table IX suggests that this is the case, a result consistent with previous observations. Time series plots of transaction prices and subsequent analysis suggest that prices converge to fundamental value and reflect private information. M oreover, although at least one informed agent is involved 
in period B transactions 62 percent of the time, the informed are unable to consistently generate superior trading profit.

As discussed in the previous subsection, the results suggest that both the informed and uninformed advance trades when the trigger of a circuit breaker may cause trading to cease. Nonetheless, market structure does not have a significant effect on traders' abilities to generate profit.

\section{Discussion and Concluding Remarks}

In this study, we use an experimental method to analyze the impact of circuit breakers on price dynamics, trading volume, and profit-making ability. We examine behavior in three institutional settings: (1) markets with mandated closures, (2) markets with temporary trading halts, and (3) markets with no interruptions. The objective of the study is to gain insight into the behavior of investors in naturally occurring markets under alternative market structures.

A $n$ important finding is that the absolute deviation in price from the expected price is not significantly different across regulatory regimes. The primary driver of deviations in price from fundamental value is the level of information asymmetry in the market. Our analysis of trading volume reveals that circuit breakers affect trading activity in a significant way. In particular, a circuit breaker rule calling for mandatory market closure has a dramatic impact on trading activity. Finally, market closures and temporary halts do not effect trading profits in a significant way.

Our results suggest that mandated trading interruptions are not meaningful impediments to pricing efficiency. However, an important distinction arises when we 
consider the form of the circuit breaker rule. When the circuit breaker rule calls for the market to close for the remainder of a trading period, traders attempt to make advantageous trades faster. Such behavior is consistent with Subrahmanyam's (1994) argument that mandated trading halts cause market participants to advance trades, a suboptimal trading strategy. $Y$ et, market structure did not have a significant effect on trading profit or price deviations from fundamental value.

Additional insight is gained by examining participants' responses to the postexperiment questionnaire. Participants were asked how the possibility of an interruption in trading would affect their behavior, if at all. Participants in the market closure treatment frequently responded that they advanced their trades. For example, one participant noted that he "tried to get that first trade in ASA P. M ake a sell or buy quickly if I knew the distribution." Others responded that they "had to be faster in accepting to buy or sell because trading could stop" and that the "possibility of interruption made me aggressive." In contrast, participants in the temporary trading halt treatment responded that there was "no effect" and that the possibility of a halt "didn't change the strategy much." $N$ ot one participant stated that the temporary breaker lead them to advance trades.

Participants' responses on the post-experiment questionnaire provide further insight into the differential effect of mandated market closures and temporary halts. Although most participants in the temporary halt sessions said the possibility of a halt had little effect on behavior, several indicated that the trading interruption provided time to assimilate information. For example, one participant stated that the possibility 
of a halt "gave me more time to think and consider my prices." According to another, it allowed him to "take a step back" and "prepare a strategy."

Regulators and policy makers clearly exercise caution before permanently shutting down markets. The circuit breakers currently in effect (described in Table I) suggest that regulators and policy makers recognize the costs of market closure as it takes a dramatic 30 percent drop in value to close the nation's exchanges for the day.

In this study we examine only rule-based trading halts. Future research may compare market behavior under rule-based and discretionary halts. Subrahmanyam (1995) shows theoretically that halts triggered at the discretion of exchange officials can be more effective than rule-based halts as discretionary halts bring more information into the decision. 


\section{FOOTNOTES}

${ }^{1}$ Trading restrictions include the NY SE's Rule $80 \mathrm{~A}$ that restricts stock index arbitrage. Trading halt rules include the price limits commonly imposed in futures markets and firm-specific trading halts called in response to order flow imbalances or pending news releases.

${ }^{2} \mathrm{Harris}$ (1998) provides a critical review of the literature.

${ }^{3}$ The original circuit breakers were never actually triggered. The wider breakers adopted in 1997 were triggered for first time on October 27, 1997. The drop in the DJIA on that day was 554.26 points or 7.2 percent.

4 See M CDaniel and Hand (1996) for further discussion of the benefits of an experimental approach.

${ }^{5}$ With a circuit breaker rule, a trader may concentrate trades rather than spreading them across time. Dispersed trades are optimal because the price impact is reduced. ${ }^{6}$ A lthough they receive a common dividend, participants trade certificates in our experiment because of divergent, uncontrolled preferences.

7 In our experimental setting, information narrows the range of dividend values but does not identify the dividend with certainty. The design reflects the fact that prices in naturally occurring markets respond to new information pertaining to shifts in the process that generates fundamental value.

${ }^{8}$ The instructions are available from the authors upon request.

9 The dividend per period, including the distributions for periods $B$ and $C$, is determined randomly by the experimenters prior to the experiment and the same sequence is used across all markets. See Cason and Friedman (1996) on the benefits of using a pre-selected sequence.

${ }_{10}$ All traders are informed the same number of times throughout the experiment.

${ }^{11}$ The specific dollar ranges are detailed in the experimental instructions that are available from the authors upon request.

12 Participants' responses to the post-experiment questionnaire suggest that they found the experiment interesting and the monetary incentives motivating. Participants responded on a seven-point scale as to how interesting they found the experiment, where $1=$ not very interesting and $7=$ very interesting. The mean response was 6.22. Participants also responded on a seven-point scale as to how they would characterize the amount of money earned for taking part in the experiment, where $1=$ nominal amount and $7=$ considerable amount. The mean response was 4.44.

${ }^{13}$ The frequencies of halts triggered by upward and downward price movements are similar across the market closure and temporary halt regimes. Time series graphs of transaction prices do not suggest divergent behavior when prices move toward the upper or lower breaker.

${ }^{14}$ Experimental bubbles markets consistently report price run-ups followed by crashes relative to fundamental value (Smith, Suchanek, Williams (1988)). In these markets, as in ours, participants trade finite-lived certificates with a common dividend determined by a probability distribution at year-end. We do not report price bubbles in our markets because of the short time horizon ( 3 periods). A nother distinction between 
our study and bubbles markets is that in our study the probability distribution that determines the dividend is not fixed and known by traders at the beginning of each market year.

${ }^{15}$ When we include all transactions the results are similar to those reported subsequently. Inferences are also unaffected if we use the average transaction price in periods $\mathrm{A}$ and $\mathrm{C}$.

${ }^{16}$ When we use data from years $1-3$, the results are similar to those reported using data from years 1-6.

${ }^{17}$ Inferences are unaffected when we define the dependent variable to be the number of transactions per period before the first trading interruption. Following this approach, we ignore trading activity that occurs after the first trading halt per period in the temporary halt regime.

${ }^{18}$ We also perform an A NOVA with the dependent variable defined as the profit generated in periods $B$ and $C$ (i.e., the difference in a trader's cash balance at the end of period $\mathrm{C}$ and the beginning of period $\mathrm{B}$ ). Inferences are unchanged.

${ }_{19}$ These mean yearly profit figures appear large until one recalls that a participant's take home earnings are 10 percent of experimental profits. 


\section{REFERENCES}

Ackert, Lucy F., and Bryan K. Church, 1998, Information dissemination and the distribution of wealth: Evidence from experimental asset markets, J ournal of Economic Behavior and Organization 37(3), 357-371.

A ckert, L ucy F., Bryan K. Church, and M ohamed Shehata, 1997, M arket behavior in the presence of costly, imperfect information: Experimental evidence, J ournal of Economic Behavior and Organization 33(1), 61-74.

Cason, Timothy N., and Daniel Friedman, 1996, Price formation in double auction markets, Journal of Economic Dynamics and Control 20(8), 1307-1337.

Copeland, Thomas E., and Daniel Friedman, 1992, The market value of information: Some experimental results, J ournal of Business 65(2), 241-266.

Coursey, D on L., and Edward A. Dyl, 1990, Price limits, trading suspensions, and the adjustment of prices to new information, Review of Futures Markets 9 (2), 342360.

Forsythe, Robert, Thomas R. Palfrey, and Charles R. Plott, 1982, A sset valuation in an experimental asset market, E conometrica 50(3), 537-567.

Forsythe, Robert, Thomas R. Palfrey, and Charles R. Plott, 1984, Futures markets and informational efficiencies: A laboratory examination, J ournal of Finance 39(4), 955-981.

Gerety, M ason S., and J. Harold M ulherin, 1992, Trading halts and market activity: A $n$ analysis of volume at the open and close, J ournal of Finance 47(5), 17651784.

Greenwald, Bruce C., and J eremy C. Stein, 1991, Transactional risk, market crashes, and the role of circuit breakers, J ournal of Business 64 (4), 443-462.

Grossman, Sanford J., and J oseph E. Stiglitz, 1976, Information and competitive price systems, American Economic Review 66(2), 246-253.

Grossman, Sanford J., and J oseph E. Stiglitz, 1980, On the impossibility of informationally efficient markets, American Economic Review 70(3), 393-408.

Harris, Lawrence E., 1998, Circuit breakers and program trading limits: W hat have we learned?, Brookings-W harton Papers on Financial Services, forthcoming. 
Hays, W.L., 1981, Statistics, 3rd edition, New Y ork: Rinehart and Winston Publishers.

Isaac, R. M ark, and Charles R. Plott, 1981, Price controls and the behavior of auction markets: An experimental examination, American Economic Review 71(3), 448459.

King, Ronald R., Vernon L. Smith, A rlington W. Williams, and M ark V an Boening, 1993, The robustness of bubbles and crashes in experimental stock markets, in R. H. Day and P. Chen, eds., Nonlinear Dynamics and Evolutionary Economics, N ew Y ork: Oxford U niversity Press, 183-200.

Kuhn, Betsey A., Gregory J. Kuserk, and Peter Locke, 1990, Do circuit breakers moderate volatility? Evidence from October 1989, working paper, Washington, D.C.: U nited States Department of A griculture.

Kyle, Albert S., 1985, Continuous auctions and insider trading, Econometrica 53(6), 1315-1335.

Lauterbach, Beni, and U ri Ben-Zion, 1993, Stock market crashes and the performance of circuit breakers: Empirical evidence, J ournal of Finance 48(5), 1909-1925.

Lee, Charles N. C., M ark J. Ready, and Paul J. Seguin, 1994, V olume, volatility, and $\mathrm{N}$ ew $\mathrm{Y}$ ork Stock Exchange trading halts, J ournal of Finance 49(1), 183-214.

M a, Christopher K., Ramesh P. Rao, and R. Stephen Sears, 1989a, Limit moves and price resolution: The case of the treasury bond futures market, J ournal of Futures Markets 9(4), 321-335.

M a, Christopher K., Ramesh P. Rao, and R. Stephen Sears, 1989b, V olatility, price resolution, and the effectiveness of price limits, J ournal of Financial Services Research 3(2-3), 165-199.

M cD aniel, Linda S., and J ohn R. M. Hand, 1996, The value of experimental methods for practice-relevant research, Contemporary Accounting Research 13(1), 33951.

Overdahl, James, and Henry M cM illan, 1998, A nother day, another collar: A n evaluation of the effects of NYSE rule $80 \mathrm{~A}$ on trading costs and intermarket arbitrage, Journal of Business 71(1), 27-53.

Presidential Task Force on M arket M echanisms, 1988, The Report of the Presidential Task Force on M arket M echanisms (Brady Report). Washington, D. C.: Government Printing Office. 
Santoni, G. J., and Tung Liu, 1993, Circuit breakers and stock market volatility, J ournal of Futures Markets 13(3), 261-277.

Smith, V ernon L., Gerry L. Suchanek, and A rlington W. Williams, 1988, Bubbles, crashes, and endogenous expectations in experimental spot asset markets, Econometrica 56(5), 1119-1151.

Smith, Vernon L., and A rlington W. Williams, 1981, On nonbinding price controls in a competitive market, American Economic Review 71(3), 467-474.

Subrahmanyam, A vanidhar, 1994, Circuit breakers and market volatility: A theoretical perspective, J ournal of Finance 49(1), 237-254.

Subrahmanyam, A vanidhar, 1995, On rules versus discretion in procedures to halt trade, J ournal of Economics and Business 47(1), 1-16.

Sunder, Shyam, 1992, M arket for information: Experimental evidence, Econometrica 60(3), 667-695.

Williams, A rlington W., 1980, Computerized double-auction markets: Some experimental results, J ournal of Business 53(3), 235-258. 


\section{Table I \\ Circuit Breaker History}

This table provides details on U.S. circuit breaker rules since they were first put in place in response to the market crash of October 1987. The original circuit breakers were triggered when the DJIA moved by a given number of points. M ore recently, actual point levels are fixed quarterly based on the average closing level of the Dow industrials in the previous month.

- First circuit breaker implemented in October 1988

250 point drop in DJIA Trading halt for one hour

400 point drop in DJIA Trading halt for two hours if additional 150 point drop after trading resumes

- Circuit breakers widened in January 1997

350 points drop in DJIA Trading halt for half an hour

550 points drop in DJIA Trading halt for one hour if additional 200 point drop after trading resumes

- Current circuit breaker rule adopted in F ebruary 1998

$10 \%$ drop

Halt trading for one hour if before 2:00 p.m.

Halt trading for 30 minutes if between 2:00 and 2:30 p. m.

No halt in trading if after 2:30 p.m.

$20 \%$ drop

Halt trading for 2 hours if before 1:00 p.m.

Halt trading for 1 hour if between 1:00 and 2:00 p.m.

Close the market for the day if after 2:00 p.m.

$30 \%$ drop

Close the market for the day 


\section{Table II \\ Overview of the Experiment}

This table provides information on the parameters of our experiment, including how dividend payments are determined. The dividends received for each certificate held at the end of periods $B$ and $C$ are determined randomly from one of the distributions I-V, whereas the dividend received at the end of period $A$ is always determined using distribution III. Each dividend is equally likely so that the average dividend per period over many draws is $\$ 5.00$.

Panel A: Experimental Parameters

\begin{tabular}{|l|c|c|}
\hline \multirow{3}{*}{ Regulatory Regime } & Markets 1-3 & M arket closure \\
\cline { 2 - 3 } & Markets 4-6 & Temporary halt \\
\cline { 2 - 3 } Fraction Informed & Markets 7-9 & No interruption \\
\hline \multirow{3}{*}{ Endowments (certificates, cash) } & Period A & $0 / 8$ \\
\cline { 2 - 3 } & Period B & $2 / 8$ \\
\hline \multirow{2}{*}{} & Period C & $8 / 8$ \\
\hline Fixed cost & $1, \$ 125.00$ \\
\hline Payout ratio & $2, \$ 110.00$ \\
\cline { 2 - 3 } & & $3, \$ 95.00$ \\
\hline
\end{tabular}

Panel B: Distribution of Dividends

\begin{tabular}{|c|c|c|c|c|c|c|c|c|}
\hline Distribution & \multicolumn{7}{|c|}{ Possible Dividends (E qually likely) } & $\begin{array}{c}\text { A verage } \\
\text { Dividend }\end{array}$ \\
\hline I & $\$ 1.50$ & $\$ 2.00$ & $\$ 2.50$ & $\$ 3.00$ & $\$ 3.50$ & $\$ 4.00$ & $\$ 4.50$ & $\$ 3.00$ \\
\hline II & $\$ 2.50$ & $\$ 3.00$ & $\$ 3.50$ & $\$ 4.00$ & $\$ 4.50$ & $\$ 5.00$ & $\$ 5.50$ & $\$ 4.00$ \\
\hline III & $\$ 3.50$ & $\$ 4.00$ & $\$ 4.50$ & $\$ 5.00$ & $\$ 5.50$ & $\$ 6.00$ & $\$ 6.50$ & $\$ 5.00$ \\
\hline IV & $\$ 4.50$ & $\$ 5.00$ & $\$ 5.50$ & $\$ 6.00$ & $\$ 6.50$ & $\$ 7.00$ & $\$ 7.50$ & $\$ 6.00$ \\
\hline V & $\$ 5.50$ & $\$ 6.00$ & $\$ 6.50$ & $\$ 7.00$ & $\$ 7.50$ & $\$ 8.00$ & $\$ 8.50$ & $\$ 7.00$ \\
\hline
\end{tabular}




\section{Table III \\ Descriptive Data on Trading Time for the \\ $M$ arket Closure and Temporary Halt Regimes}

F or each period and year, the table presents the average number of seconds the markets in the market closure and temporary halt regimes are open for trading. Sessions with no circuit breaker rule are always open 180 seconds per period, which is the maximum number of seconds for trading across all market structures.

\begin{tabular}{|c|c|c|c|}
\hline \multirow{2}{*}{ Y ear } & Period & $\begin{array}{c}\text { Market } \\
\text { Closure }\end{array}$ & $\begin{array}{c}\text { Temporary } \\
\text { Halt }\end{array}$ \\
\hline \multirow{4}{*}{1} & A & 174 & 160 \\
\cline { 2 - 4 } & B & 87 & 150 \\
\cline { 2 - 4 } & C & 99 & 160 \\
\hline \multirow{4}{*}{2} & A & 128 & 170 \\
\cline { 2 - 4 } & B & 110 & 150 \\
\cline { 2 - 4 } & C & 47 & 150 \\
\hline \multirow{4}{*}{3} & A & 129 & 170 \\
\cline { 2 - 4 } & B & 34 & 170 \\
\hline \multirow{4}{*}{4} & C & 54 & 160 \\
\cline { 2 - 4 } & A & 125 & 170 \\
\cline { 2 - 4 } & B & 47 & 170 \\
\hline \multirow{3}{*}{5} & C & 17 & 140 \\
\cline { 2 - 4 } & A & 130 & 180 \\
\cline { 2 - 4 } & B & 125 & 170 \\
\cline { 2 - 4 } & C & 31 & 180 \\
\hline \multirow{3}{*}{6} & A & 124 & 130 \\
\cline { 2 - 4 } & B & 67 & 130 \\
\hline Average & C & 60 & 160 \\
\hline
\end{tabular}




\section{Table IV \\ Descriptive Data on the Frequency of Trading Halts, Draws, and Transactions}

In Panel A (B), the table presents the number of halts and draws by period (year) for the market closure and temporary halt sessions. Also reported is the total number of transactions for all three market structures.

Panel A: F requencies by Period

\begin{tabular}{|c|c|c|c|c|c|c|c|}
\hline \multirow{2}{*}{ Period } & \multicolumn{3}{|c|}{ Market Closure } & \multicolumn{3}{c|}{ Temporary Halt } & $\begin{array}{c}\text { No } \\
\text { Interruption }\end{array}$ \\
\cline { 2 - 8 } & Halts & Draws & Transactions & Halts & Draws & Transactions & Transactions \\
\hline A & 6 & 7 & 71 & 6 & 8 & 98 & 129 \\
\hline B & 14 & 29 & 50 & 13 & 23 & 84 & 78 \\
\hline C & 18 & 19 & 29 & 18 & 23 & 84 & 92 \\
\hline Total & 38 & 55 & 150 & 37 & 54 & 266 & 299 \\
\hline
\end{tabular}

Panel B: F requencies by $\mathrm{Y}$ ear

\begin{tabular}{|c|c|c|c|c|c|c|c|}
\hline \multirow{2}{*}{ Y ear } & \multicolumn{3}{|c|}{ M arket Closure } & \multicolumn{3}{c|}{ Temporary Halt } & $\begin{array}{c}\text { No } \\
\text { Interruption }\end{array}$ \\
\cline { 2 - 8 } & Halts & Draws & Transactions & Halts & Draws & Transactions & Transactions \\
\hline 1 & 6 & 7 & 28 & 8 & 12 & 43 & 47 \\
\hline 2 & 6 & 9 & 25 & 7 & 8 & 41 & 51 \\
\hline 3 & 7 & 7 & 19 & 4 & 7 & 46 & 49 \\
\hline 4 & 7 & 15 & 27 & 6 & 9 & 42 & 52 \\
\hline 5 & 5 & 7 & 26 & 2 & 4 & 45 & 60 \\
\hline 6 & 7 & 10 & 25 & 10 & 14 & 49 & 50 \\
\hline Total & 38 & 55 & 150 & 37 & 54 & 266 & 309 \\
\hline
\end{tabular}




\section{Table V \\ Price Predictions}

For each period, the table presents the risk-neutral expected value or predicted price and the distribution used to determine the period's observed dividend. In Period B the predicted price is conditioned on the dissemination of private information.

\begin{tabular}{|c|c|c|c|}
\hline Y ear & Period & $\begin{array}{c}\text { Predicted } \\
\text { Price }\end{array}$ & $\begin{array}{c}\text { Dividend } \\
\text { Distribution }\end{array}$ \\
\hline \multirow[t]{3}{*}{1} & A & 15 & III \\
\hline & $B$ & 8 & \multirow[t]{2}{*}{ II } \\
\hline & $C$ & 4 & \\
\hline \multirow[t]{3}{*}{2} & A & 15 & III \\
\hline & $B$ & 12 & \multirow[t]{2}{*}{ IV } \\
\hline & $C$ & 6 & \\
\hline \multirow[t]{3}{*}{3} & A & 15 & III \\
\hline & $B$ & 6 & \multirow[t]{2}{*}{1} \\
\hline & $C$ & 3 & \\
\hline \multirow[t]{3}{*}{4} & A & 15 & III \\
\hline & $B$ & 12 & \multirow[t]{2}{*}{ IV } \\
\hline & $C$ & 6 & \\
\hline \multirow[t]{3}{*}{5} & A & 15 & III \\
\hline & $B$ & 10 & \multirow[t]{2}{*}{ III } \\
\hline & $C$ & 5 & \\
\hline \multirow[t]{3}{*}{6} & A & 15 & III \\
\hline & $B$ & 14 & \multirow[t]{2}{*}{ V } \\
\hline & $C$ & 7 & \\
\hline
\end{tabular}




\section{Table VI \\ Analysis of Price Behavior}

The table presents the results of an ANOVA to test the effects of market structure on deviations in transaction prices from fundamental value. The dependent variable is the absolute value of the transaction price minus the predicted price, normalized by the predicted price. For periods $A$ and $C$, the transaction price used in determining the absolute deviation is the median price per period. For period $B$, the price used is the final price per period. The independent variables include market structure (market closure, temporary halt, and no interruption), period ( $A, B$, and $C)$, and an interaction term. The analysis reported in Panel A (B) includes data from years 1-6 (4-6).

Panel A: ANOVA Results using Data from Y ears 1-6

\begin{tabular}{|c|c|c|c|c|}
\hline Source & df & Sum of Squares & F-statistic & -value \\
\hline M arket & 2 & 0.0034 & 0.531 & 0.589 \\
\hline Period & 2 & 0.6020 & 9.449 & 0.000 \\
\hline Interaction & 4 & 0.2780 & 2.183 & 0.074 \\
\hline Error & 153 & 4.8730 & \multicolumn{2}{l|}{} \\
\hline
\end{tabular}

Panel b: AN OV A Results using Data from Y ears 4-6

\begin{tabular}{|c|c|c|c|c|}
\hline Source & df & Sum of Squares & F-statistic & p-value \\
\hline M arket & 2 & 0.0022 & 1.523 & 0.225 \\
\hline Period & 2 & 0.0092 & 6.408 & 0.003 \\
\hline Interaction & 4 & 0.0029 & 1.024 & 0.401 \\
\hline Error & 72 & 0.5150 & \multicolumn{2}{l}{} \\
\hline
\end{tabular}




\section{Table VII \\ Analysis of Trading Volume}

The table presents the results of an ANOVA to test the effects of market structure on trading volume. The dependent variable is the number of transactions per period normalized by the number of seconds that the market is open for trading. The independent variables include market structure (market closure, temporary halt, and no interruption), period $(A, B$, and $C)$, and an interaction term. The analysis reported in Panel A (B) includes data from years 1-6 (4-6).

Panel A: ANOVA Results using Data from Y ears 1-6

\begin{tabular}{|c|c|c|c|c|}
\hline Source & df & Sum of Squares & F-statistic & $p$-value \\
\hline M arket & 2 & 0.0005 & 8.803 & 0.000 \\
\hline Period & 2 & 0.0000 & 0.698 & 0.499 \\
\hline Interaction & 4 & 0.0004 & 3.877 & 0.005 \\
\hline Error & 153 & 0.0043 & & \\
\hline
\end{tabular}

Panel B: ANOVA Results using Data from Y ears 4-6

\begin{tabular}{|c|c|c|c|c|}
\hline Source & df & Sum of Squares & F-statistic & p-value \\
\hline M arket & 2 & 0.0007 & 11.642 & 0.000 \\
\hline Period & 2 & 0.0000 & 0.410 & 0.665 \\
\hline Interaction & 4 & 0.0002 & 7.832 & 0.132 \\
\hline Error & 72 & 0.0022 & & \\
\hline
\end{tabular}




\section{Table VIII \\ Analysis of Trading by Informedness}

The table presents the results of univariate ANOVAs to test the effects of market structure on informed and uninformed trading in period $B$. The dependent variables are the number of transactions for informed and uninformed traders in period $B$ normalized by the number of seconds that the market is open for trading that period. The independent variable is market structure (market closure, temporary halt, and no interruption). The analysis reported in Panel A (B) includes data from years 1-6 (4-6).

Panel A: U nivariate A NOVA Results using Data from Y ears 1-6

\begin{tabular}{|c|c|c|c|c|c|}
\hline $\begin{array}{c}\text { Dependent } \\
\text { Variable }\end{array}$ & Source & $\mathrm{df}$ & $\begin{array}{c}\text { Sum of } \\
\text { Squares }\end{array}$ & F-statistic & $p$-value \\
\hline \hline $\begin{array}{c}\text { Informed } \\
\text { Trades }\end{array}$ & M arket & 2 & 0.0003 & 4.482 & 0.016 \\
\cline { 2 - 6 } & Error & 51 & 0.0020 & & \\
\hline \hline $\begin{array}{c}\text { Uninformed } \\
\text { trades }\end{array}$ & M arket & 2 & 0.0006 & 7.623 & 0.001 \\
\cline { 2 - 6 } & Error & 51 & 0.0022 & & \\
\hline
\end{tabular}

Panel B: Univariate A NOVA Results using D ata from Y ears 4-6

\begin{tabular}{|c|c|c|c|c|c|}
\hline $\begin{array}{c}\text { Dependent } \\
\text { Variable }\end{array}$ & Source & $\mathrm{df}$ & $\begin{array}{c}\text { Sum of } \\
\text { Squares }\end{array}$ & F-statistic & $\mathrm{p}$-value \\
\hline \hline \multirow{2}{*}{$\begin{array}{c}\text { Informed } \\
\text { Trades }\end{array}$} & M arket & 2 & 0.0004 & 3.839 & 0.036 \\
\cline { 2 - 6 } & Error & 24 & 0.0012 & & \\
\hline \hline \multirow{2}{*}{$\begin{array}{c}\text { Uninformed } \\
\text { trades }\end{array}$} & M arket & 2 & 0.0005 & 4.899 & 0.016 \\
\cline { 2 - 6 } & Error & 24 & 0.0013 & & \\
\hline
\end{tabular}




\section{Table IX \\ A nalysis of Trading Profit}

The table presents the results of an ANOVA to test the effects of market structure on traders' ability to generate profit. The dependent variable is the profit generated per trader each year. The independent variables include market structure (market closure, temporary halt, and no interruption), informedness (informed and uninformed), and an interaction term. The analysis reported in Panel A (B) includes data from years 1-6 (4$6)$.

Panel A: ANOVA Results using Data from Y ears 1-6

\begin{tabular}{|c|c|c|c|c|}
\hline Source & df & Sum of Squares & F-statistic & p-value \\
\hline M arket & 2 & 103 & 0.110 & 0.896 \\
\hline Informedness & 1 & 1,277 & 2.724 & 0.100 \\
\hline Interaction & 2 & 745 & 0.794 & 0.452 \\
\hline Error & 426 & 199,681 & & \\
\hline
\end{tabular}

Panel B: ANOVA Results using Data from Y ears 4-6

\begin{tabular}{|c|c|c|c|c|}
\hline Source & df & Sum of Squares & F-statistic & p-value \\
\hline M arket & 2 & 8 & 0.008 & 0.992 \\
\hline Informedness & 1 & 743 & 1.585 & 0.209 \\
\hline Interaction & 2 & 158 & 0.337 & 0.714 \\
\hline Error & 210 & 98,454 & & \\
\hline
\end{tabular}


Figure 1

Transaction Prices

Predicted Price

------ Circuit Breaker (90\%)

- - Circuit Breaker (50\%)

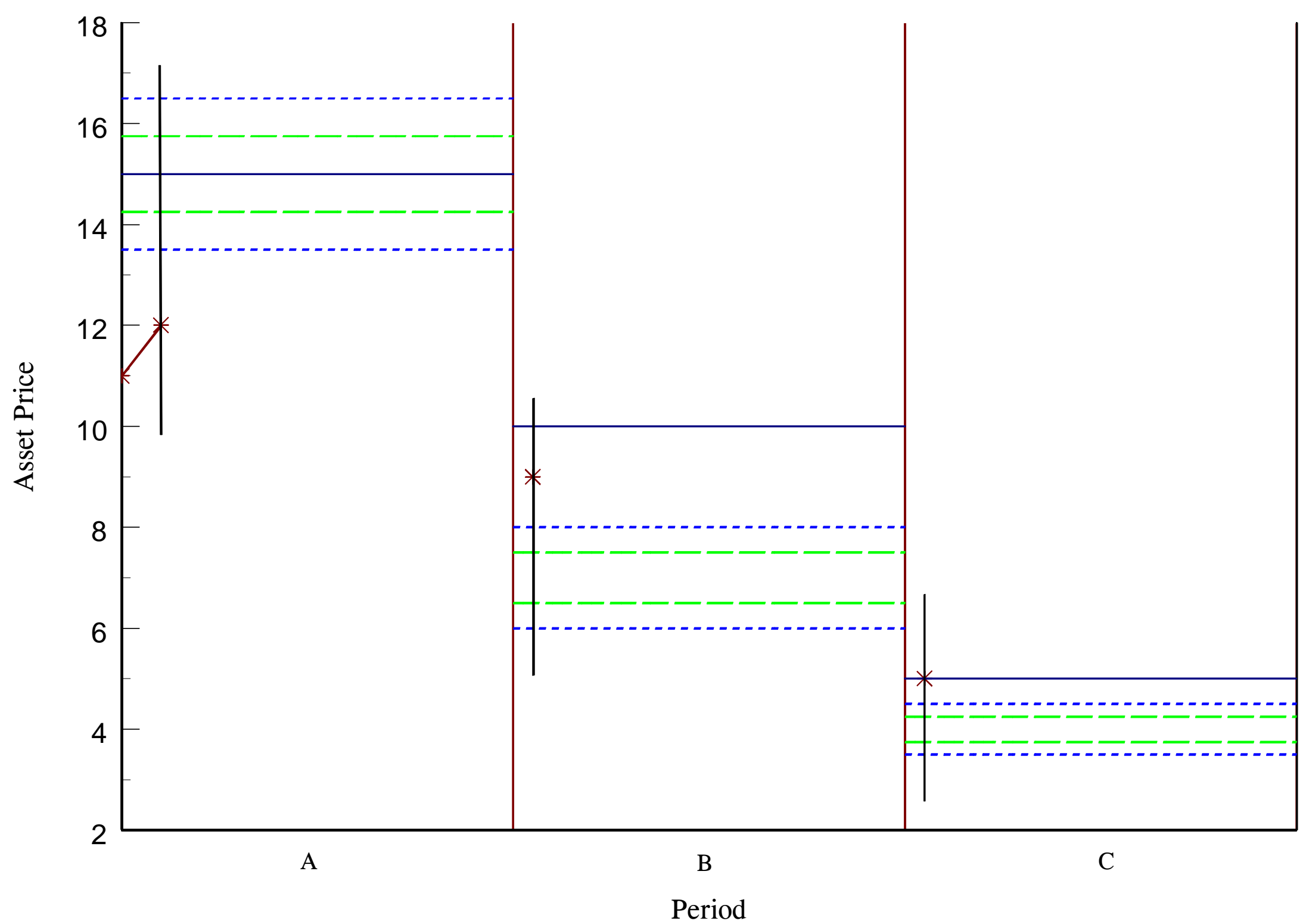


Figure 2

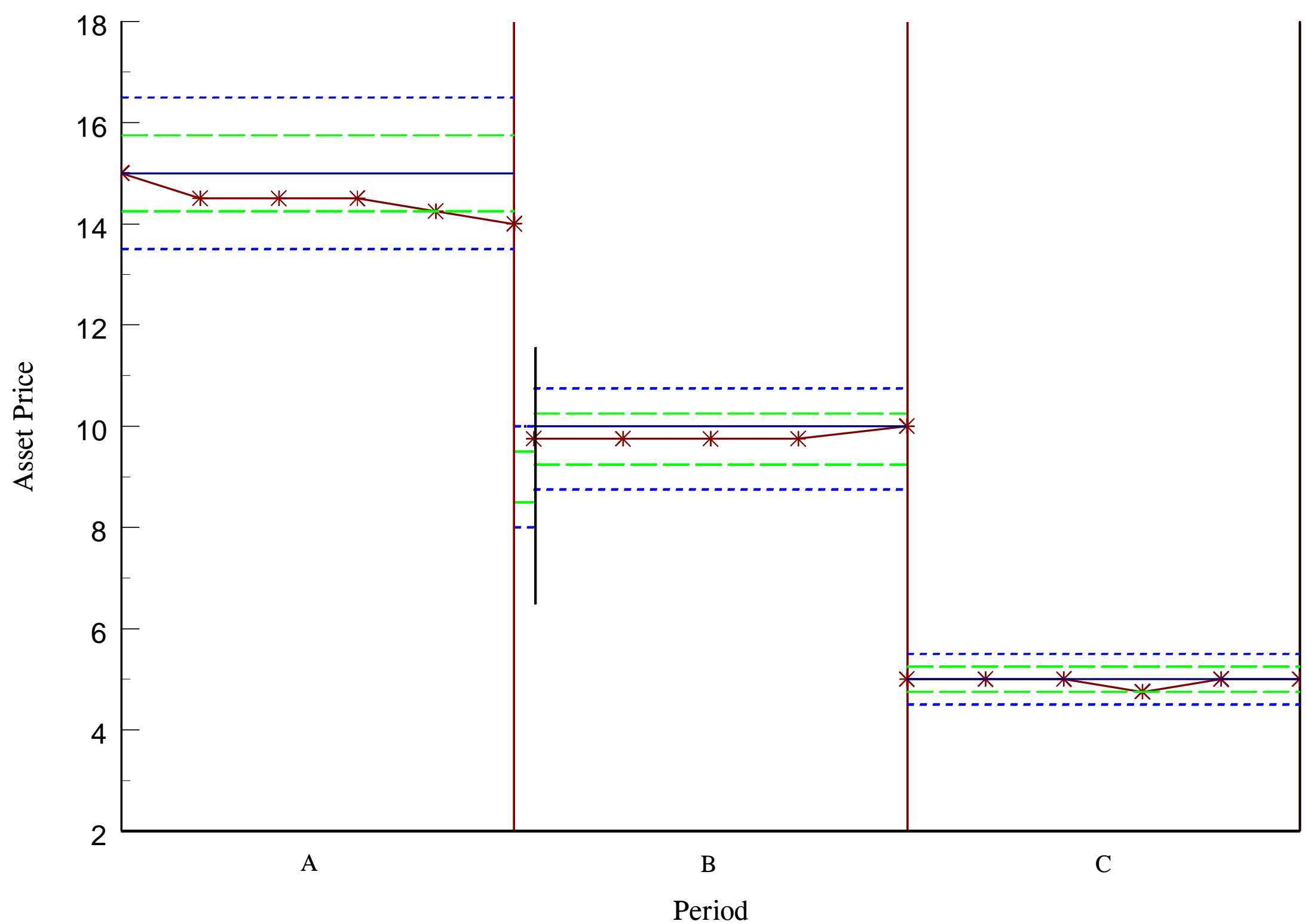


Figure 3

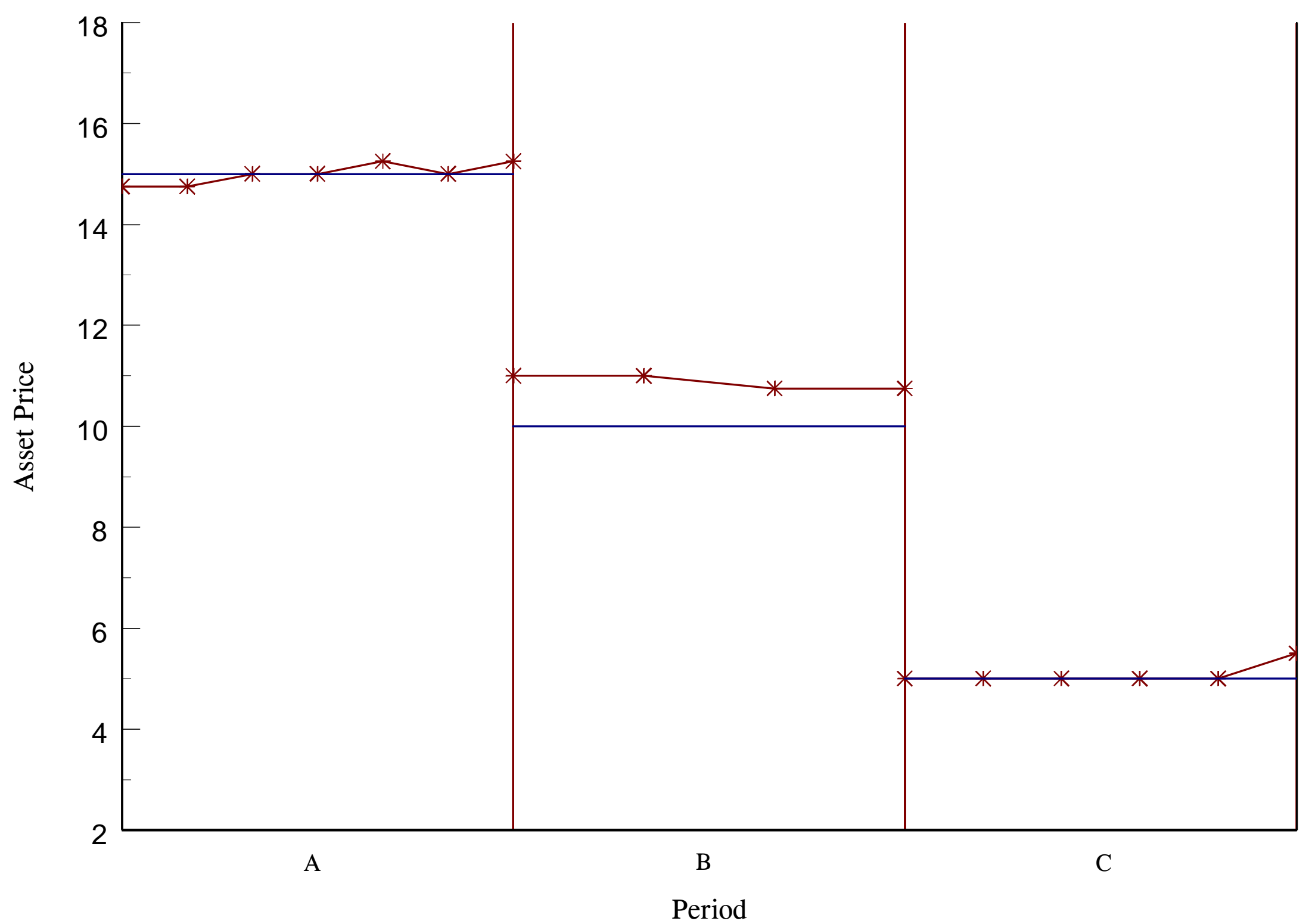


Figure 4

Transaction Prices

Predicted Price

---.-- Circuit Breaker (90\%)

- - Circuit Breaker (50\%)

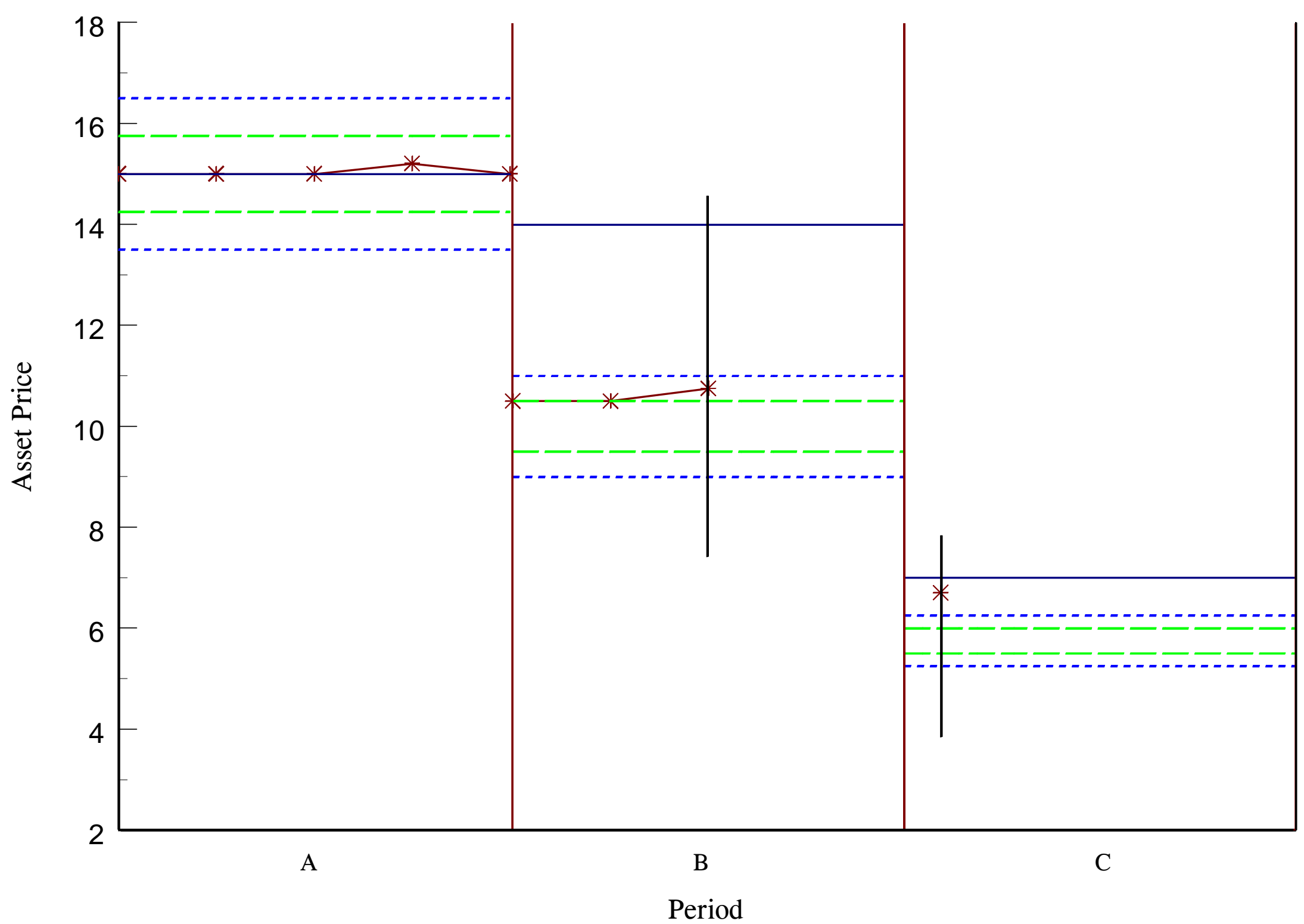


Figure 5

Transaction Prices

\begin{tabular}{ll}
- & Predicted Price \\
\hline$-\ldots-1$ & Circuit Breaker (90\%)
\end{tabular}

- $-\quad$ Circuit Breaker (50\%)

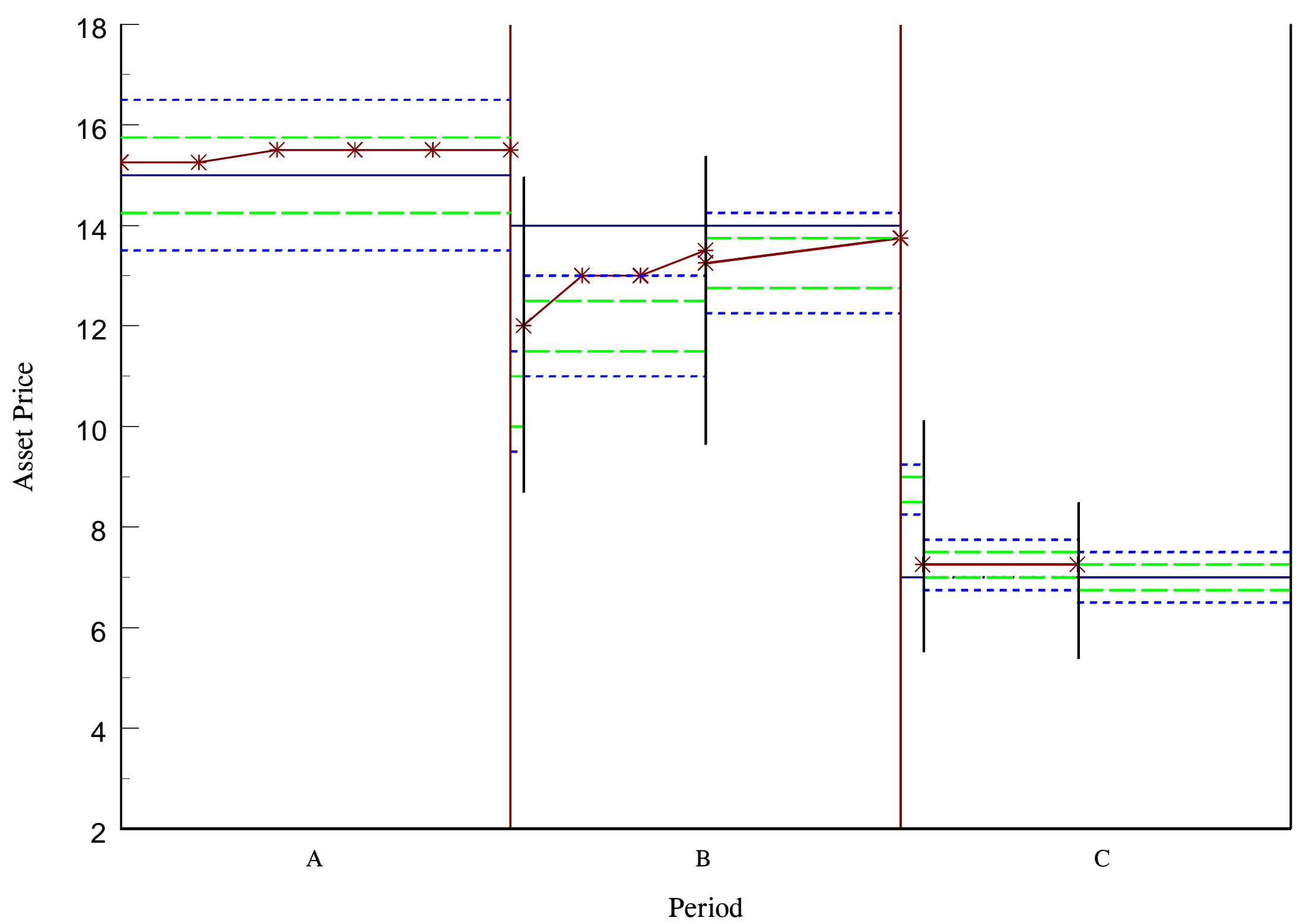


Figure 6

Transaction Prices

Predicted Price

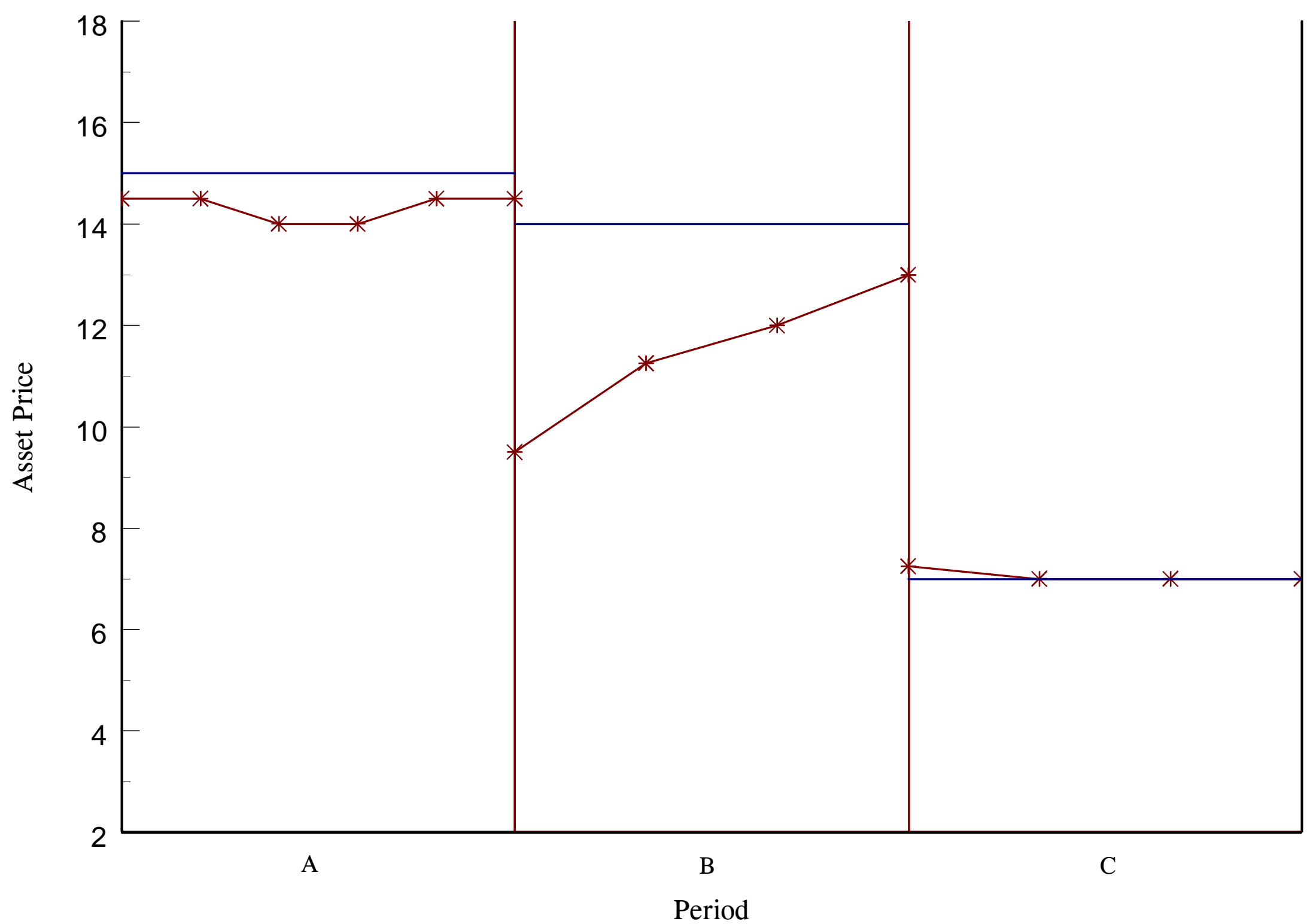

